\title{
Desafios para o professor na sociedade da informação
}

\section{Challenges for teachers in the information society}

\author{
Ana Paula Domingos Baladeli ${ }^{1}$ \\ Marta Silene Ferreira Barros ${ }^{2}$ \\ Anair Altoé 3
}

\begin{abstract}
RESUMO
As tecnologias da informação e da comunicação - TIC - ganham evidência em um contexto de amplo investimento científico e tecnológico. As TIC promovem alterações na produção, no armazenamento e na divulgação de informação e de conhecimento. Este trabalho tem o propósito de discutir os impactos da sociedade da informação na educação engendrados pelo discurso da democratização do conhecimento. Para tanto, buscou-se em pesquisas de Castells (2000), Schaff (1995), Lévy (1999), Mattelart (2006), Frigotto (1996), e Nagel (2002) a conceituação da sociedade da informação a fim de compreender o papel das tecnologias nesse contexto. A análise apontou os desafios para o professor para atuação crítica com tecnologias uma vez que o aumento no acesso à informação gera questionamentos sobre as abordagens educacionais tradicionais. Análises feitas por Altoé (2003), Teruya (2006), Brito e Purificação (2008) revelam a necessidade de formação do professor para análise crítica e reflexiva para o uso de tecnologias em sua prática pedagógica. Assim, o referencial adotado possibilitou a apreciação crítica a respeito das características da sociedade da informação e as implicações
\end{abstract}

1 Doutoranda em Letras (Linguagem e Sociedade) pela Universidade Estadual do Oeste do Paraná (Unioeste). Professora colaboradora no colegiado de Pedagogia da Unioeste campus de Cascavel, Brasil. E-mail: annapdomingos@yahoo.com.br.

2 Doutora em Educação pela Universidade de São Paulo. Professora Adjunta do Departamento de Educação da Universidade Estadual de Londrina (UEL), Brasil. E-mail: mbarros_22@ hotmail.com.

3 Doutora em Educação (Currículo) pela Pontifícia Universidade Católica de São Paulo (PUC/SP). Professora do Programa de Pós-Graduação em Educação (PPE) da Universidade Estadual de Maringá (UEM), Brasil. E-mail: aaltoe@uem.br. 
no papel do professor diante do uso crescente de tecnologias.

Palavras-chave: educação; formação do professor; tecnologias da informação e comunicação.

\begin{abstract}
Information and communication technologies - ICT are prominence in a large context of scientific and technological investments. ICT promote changes in production, storage, and dissemination of information and knowledge. This way the present article intends to discuss the impact of information society in education based on the discourse about the democracy of knowledge. For that, some research by Castells (2000), Schaff(1995), Lévy (1999), Mattelart (2006), Frigotto, (1996), and Nagel (2002) were consulted to conceptualize the information society in order to comprehend the role of the technologies in this context. The challenges of teachers to act critically with technologies are expanded increasingly in the access of information which cause discussions about the traditional approach education. Analyses done by Altoé (2003), Teruya (2006) and Brito \& Purificação (2008) revealed the necessity of teacher training for a critical and reflexive study about the use of technologies in the pedagogical practice. Thus, the references consulted assisted the critical view about the characteristics of information society and the implications to teacher's role in face of the increasingly use of technologies.
\end{abstract}

Keywords: education; teacher training; information and communication technologies.

\title{
Introdução
}

Os avanços científicos e tecnológicos presentes no mundo moderno provocam novas formas de se conceber o processo educativo, sendo o mesmo agravado pela expansão das tecnologias da informação e comunicação - TIC. Por essa razão, é requerido um novo perfil de professor que saiba atuar criticamente com tecnologias e compreenda as mudanças que o uso delas imprime em sua prática pedagógica (TERUYA, 2006; BRITO; PURIFICAÇÃO, 2008).

A nova dinâmica regida pelas tecnologias impulsiona o surgimento de novos paradigmas tanto de ensino quanto de aprendizagem. Dessa forma, a adequação da educação às novas tendências trazidas pela sociedade da informação e do conhecimento, bem como a formação e o papel do professor do século XXI, 
também tendem a serem postos à prova, isso porque, no presente contexto, a informação e o conhecimento ganham destaque tanto política quanto socialmente. Em função da abertura comercial da Internet (rede mundial de computadores) em 1995, a produção, o armazenamento e a divulgação de informação ganham novos espaços (CASTELLS, 2000; BRITO; PURIFICAÇÃO, 2008).

Por conta dessa tecnologia cuja abrangência não encontra limites, a atualização e o aperfeiçoamento constante são as palavras-chave desse momento histórico para aqueles que buscam maiores chances de empregabilidade num mercado cada vez mais competitivo (FRIGOTTO, 1996; TERUYA, 2006). Levando esse contexto em consideração, a educação, bem como as práticas pedagógicas tradicionais, vem sendo discutida tendo em vista o aparecimento de novas formas de mediação e acesso ao conhecimento. Hoje, o professor depara-se com um cenário multifacetado em que a celeridade e a mobilidade ditam o ritmo das mudanças sociais.

Fato inconteste, a valorização atribuída à informação e ao conhecimento aumenta o debate a respeito do papel da educação como instituição formadora e sua adequação à demanda por um novo perfil de homem (TERUYA, 2006). Tal valorização promove a ascensão da informação e do conhecimento à condição de mercadoria, o que corrobora para a concretização do discurso neoliberal, que tem na democratização do conhecimento o seu maior argumento (SCHAFF, 1995; NAGEL, 2002).

Mattelart (2006) adverte que o caráter de novidade atribuído ao discurso sobre o mercado global e ampla divulgação da informação é equivocado, até porque, segundo o sociólogo, o conjunto de inovações vivenciadas no tempo moderno é "[...] produto de evoluções estruturais e de processos que estão em curso há muito tempo" (MATTELART, 2006, p. 174).

Nessa perspectiva, as tecnologias da informação e da comunicação promoveriam o acesso ilimitado aos recursos e a diferentes linguagens que emanam com as tecnologias, porém, o que se percebe na prática é que as condições objetivas para que as pessoas acessem esses recursos não são as mesmas, dado que revela novas dimensões da exclusão.

Dessa forma, objetivamos com a elaboração deste trabalho discutir a constituição da sociedade da informação e do conhecimento, as implicações tanto sociais quanto educacionais, com a expansão das TIC, e os desafios da educação num contexto em que a informação e o conhecimento ganham destaque e relevância. 


\section{Sociedade da informação e do conhecimento}

Para iniciarmos a discussão a respeito das implicações decorrentes dos avanços científicos e tecnológicos e da abrangência das TIC faz-se necessária a discussão de dois conceitos forjados para representar a sociedade da informação e do conhecimento.

Nosso ponto de partida, pois, é a obra Sociedade em Rede (2000) do sociólogo catalão Manuel Castells, em que apresenta a definição de Sociedade em Rede para definir o momento histórico moderno de amplo investimento, desenvolvimento e divulgação de recursos tecnológicos. Ainda segundo o autor, a origem dessa sociedade interligada em rede está condicionada ao sistema capitalista, esse que se reestruturou em meados da década de 80 do século XX tendo como agente norteador a revolução tecnológica. Essa revolução cumpriu o papel de romper as fronteiras e encurtar distâncias num movimento de flexibilização e descentralização de mercados provocando uma nova organização social, visto que "[...] remodelam a base material da sociedade em ritmo acelerado" (CASTELLS, 2000, p. 21).

Assim, a informação e o conhecimento tornam-se elementos centrais já que novos canais de produção, processamento e divulgação de dados são necessários a fim de atender a demanda da sociedade. O surgimento do projeto ARPANET, que se tornaria mais tarde a Internet (rede de computadores interligados) em 1969, nos Estados Unidos, exemplifica o poder e a abrangência dessas redes de comunicação, uma vez que proporcionam novas formas de interação humana e, por conseguinte, a construção de novos espaços sociais. A Internet se mantém como um mecanismo comunicacional que "[...] não pode ser controlada a partir de nenhum centro e é composta por milhares de redes de computadores autônomos com inúmeras maneiras de conexão" (CASTELLS, 2000, p. 26).

Ainda na perspectiva de uma Sociedade em Rede, a geração de conhecimento, bem como a transmissão de informação, alcança um patamar significativo e atraente ao mercado global em que se tornou a sociedade, graças, sobretudo, ao fim das "distâncias" físicas. Encerrando essa breve definição de Sociedade em Rede, Castells (2000) compara o papel da tecnologia da informação no cenário atual ao mesmo papel desenvolvido pelas fontes de energia, como máquina a vapor, a eletricidade e a energia nuclear no contexto das Revoluções Industriais que a antecederam.

A nossa segunda definição para o termo sociedade da informação e do conhecimento é encontrada na obra Sociedade Informática de Adam Schaff (1995). Para o autor, o contexto atual é produto de três grandes eventos históricos 
decorrentes da revolução industrial. Tais eventos denominados de revoluções técnico-científicas (microeletrônica, microbiologia e energia nuclear). Essas revoluções imprimem transformações significativas na sociedade, modificam as qualificações no mundo do trabalho e reorganizam a base produtiva.

Segundo o autor, essas revoluções proporcionam grandes possibilidades de desenvolvimento econômico, mas em contrapartida, também sugerem mudanças na dinâmica social. Além do desemprego estrutural causado pelos avanços técnico-científicos, já que a tendência é a substituição do trabalho manual pelo trabalho realizado por máquinas modernas, a questão da manipulação da engenharia genética e mesmo dos recursos da energia nuclear a serviço dos interesses dos países proprietários dessas tecnologias também alimentam a discussão a respeito dos impactos causados pelo crescente de tecnologias. Nesse contexto, "[...] a ciência assumirá o papel de força produtiva. Mesmo hoje a força de trabalho se modifica e desaparece em sentido social. Na nova estrutura de classes da sociedade, a classe trabalhadora também desaparecerá" (SCHAFF, 1995, p. 43).

Logo, haverá a valorização de algumas profissões em detrimento de outras, isso porque as áreas relacionadas à medicina, engenharia e informática ganham maior destaque e status. Essa valorização incorrerá sobre um novo grupo de profissionais - os especialistas, grupo que será composto essencialmente por “[...] representantes das ciências (não só das disciplinas tecnológicas, mas também das ciências fundamentais como, por exemplo, a matemática, a física, a química, a biologia, etc.)" (SCHAFF, 1995, p. 45).

Ao que tudo indica estamos diante da velha dicotomia trabalho manual versus trabalho intelectual, porém, revestido de novas exigências e por que não dizer de novos conceitos trazidos, sobretudo, pelo ideário da sociedade da informação e do conhecimento. $\mathrm{O}$ trabalho tal qual o conhecemos e a ascensão de outra forma, "[...] assumirá o caráter de ocupações intelectuais, de natureza criativa, dado que o trabalho intelectual rotineiro, que consiste em realizar operações repetitivas que podem ser automatizadas, também desaparecerá" (SCHAFF, 1995, p. 46).

Ademais, a possibilidade de eliminação de classes sociais e da constituição de uma nova forma de trabalho, essa que parte das capacidades intelectuais do homem, outro perigo surge com novas desigualdades produzidas pelos avanços técnico-científicos - a divisão entre os países que dominam a tecnologia e, por isso, produz conhecimento, e aqueles que a consomem. Conforme Schaff, essa divisão entre as pessoas ou economias consistirá basicamente entre "[...] as que têm algo que é socialmente importante e as que não têm. Este "algo", no caso é a informação" (SCHAFF, 1995, p. 49). 
Como solução às próprias contradições produzidas pela lógica capitalista, a alternativa para diminuir o desemprego estrutural (possível diante da aplicação dos recursos científicos e tecnológicos em diversos postos de trabalho) é a de suscitar o discurso ideológico da formação ao longo da vida como pressuposto para a empregabilidade do sujeito e sua permanência no mercado de trabalho.

Para Nagel (2002) a sociedade da informação e do conhecimento é antes de qualquer coisa uma sociedade capitalista dividida em classes e, como tal, apresenta-se contraditória e excludente. Atualmente, o acesso e a produção de tecnologias na área de biologia, informática, telecomunicações, robótica e inteligência artificial representam capital estratégico em poder das grandes organizações e economias. Dessa forma, os países em desenvolvimento e a maior parcela da população encontram-se alheios não só a essas novas tecnologias como de outros bens materiais básicos à sobrevivência do homem.

\section{As TIC e o discurso da democratização do conhecimento}

Estamos ao longo deste artigo ressaltando as características e as implicações sociais resultantes deste momento histórico chamado de sociedade da informação e do conhecimento. Logo, ao falarmos de democratização do conhecimento não podemos deixar de abranger a dimensão ideológica a ela inerente, isso porque, qualquer que seja a tecnologia adotada para a produção e a divulgação de informação e de conhecimento, não se pode perder de vista que nenhuma tecnologia se constitui neutra (CASTELLS, 2000; TERUYA, 2006).

Por meio da tecnologia Internet, hoje em dia é possível buscar, processar e armazenar um grande volume de informações e arquivos. Todavia, vale ressaltar que na condição de meio de comunicação, a Internet propaga interesses, culturas e ideologias. Infelizmente, a maior parte da população ainda não possui acesso a revistas, jornais, ou mesmo conhecem sítios na Internet ou outros bens socialmente produzidos que possam garantir-lhe compreensão crítica da realidade.

Sendo assim, importa indagar que informação e conhecimento são divulgados pelas TIC, até porque proporcionalmente ao aumento dos recursos da tecnologia cresce uma massa de excluídos, pessoas que não possuem acesso a esses bens materiais (SCHAFF, 1995).

Para Mattelart (2006), um dos perigos desencadeados pelo discurso utópico do avanço das técnicas e das tecnologias em uma sociedade globalizada é a ausência de senso crítico sobre o contexto. Enquanto percebe-se a ampliação de pesquisas sobre os impactos da sociedade da informação na educação, surgem 
novos conceitos para descrever aqueles que ainda não aceitaram a revolução trazida pelas tecnologias, são os tecnofóbicos.

Segundo Nagel (2002), a democratização do conhecimento, principal argumento dos defensores dessa sociedade da informação, na verdade revela-se mais como um mecanismo alienante com o propósito de encobrir os reais interesses da classe dominante. A autora justifica sua análise discorrendo sobre as eternas contradições que continuarão a existir em uma sociedade essencialmente de classes, em que os recursos da tecnologia da comunicação por si só não promovem a superação da condição social ou material, ao contrário, provocam novos tipos de exclusão.

A política do estado mínimo vem complementar a responsabilidade do sujeito por suas próprias condições materiais, o que é agravado pelo crescente avanço de recursos tecnológicos. Com o aumento do uso da Internet, só para citar um exemplo mais próximo da nossa realidade, o setor empresarial ou "homens de negócios", conforme Frigotto (1996), encontra um forte aliado na pressão por atualização e aperfeiçoamento constantes de mão de obra. Outro exemplo é a educação a distância - EAD que chegou definitivamente para suprir novas demandas da sociedade moderna.

Assim, a Internet, como uma grande rede de computadores interligados, transita em todas as esferas de atividade humana contribuindo para a intolerância a profissionais acomodados que veem em sua formação acadêmica a única porta para o mercado de trabalho. Se não bastasse a competição acirrada por postos de trabalhos, já que não há espaço para todos no mercado, a empregabilidade do sujeito depende do desenvolvimento de atitudes que transitam entre a flexibilidade e a polivalência (FRIGOTTO, 1996).

Nesse contexto, o profissional nunca está formado, o conceito de formação ao longo da vida nunca fez tanto sentido para nós. Paradoxalmente, as especialidades nunca foram tão abrangentes quanto nos dias atuais. A demanda por profissionais multidisciplinares revela a necessidade de outras competências que atendam ao interesse do mercado global (FRIGOTTO, 1996; LÉVY, 1999). Constata-se que não há espaço para todos no mercado de trabalho e a seleção natural é inevitável. Pierre Lévy destaca que "pela primeira vez na história da humanidade, a maioria das competências adquiridas por uma pessoa no início de seu percurso profissional estarão obsoletas no fim de sua carreira" (LÉVY, 1999, p. 157).

A partir dessa realidade, as pressões recaem sobre a instituição escolar, pois é vista como espaço mediador entre o conhecimento socialmente construído e o sujeito. Na próxima seção discorreremos brevemente sobre as implicações que acometem o setor da educação mediante os avanços tecnológicos. 


\section{Implicações sociais e educacionais de uma sociedade em transformação}

A escola como espaço para disseminação de conhecimento historicamente produzido representa a primeira esfera de contato entre o sujeito e esse conhecimento científico. Assim, recai sobre ela a emergência na adequação de paradigmas a fim de que possibilite a formação de sujeitos consoantes com a realidade de uma sociedade globalizada. Dito de outro modo, a escola, como espaço sui generis para de formação humana, não pode estar alheia aos acontecimentos e da realidade vivenciada na sociedade, isso porque ela própria compõe essa sociedade.

Velocidade, adaptação e mobilidade são os termos que melhor representam este momento histórico que vivenciamos. A área empresarial, por exemplo, foi a primeira a redefinir os perfis de profissionais para atuação em uma sociedade em constante transformação, em que a produção, a assimilação, o armazenamento e a divulgação de informação são requeridos. Contudo, a velocidade e a quantidade de informações transmitidas pelas diversas tecnologias da informação e comunicação fazem com que essas sejam apenas assimiladas de forma muitas vezes acrítica. Assim, importa compreender a natureza da informação e do conhecimento, matéria prima da sociedade atual. Conforme Bianchetti (2001), compreende-se como informação o subsídio necessário à construção de conhecimento, nessa perspectiva nem toda informação chega a se tornar conhecimento, pois não foi recontextualizada. Por conhecimento, o autor entende que seja o estágio subsequente na compreensão e na articulação da informação com outro conhecimento.

Diante do exposto, a educação assume outros papéis sociais, com o propósito, entre outros, de promover o desenvolvimento da sociedade. Não acreditamos nesse ideário de que a educação, e somente ela, seja capaz de diminuir as mazelas da sociedade. Mesmo porque, ela própria como instituição formadora e como via de acesso ao conhecimento científico mal consegue resolver suas questões internas. As decisões políticas e econômicas a priori fazem parte das atribuições do Estado, e, via de regra, também é de sua alçada prover a sociedade com o mínimo de acesso à educação, moradia, saúde, emprego, saneamento. Apesar disso, no bojo de uma sociedade capitalista notadamente norteada por decisões neoliberais, a política do Estado mínimo complementa o cenário atual e aponta para mudanças impreteríveis na educação e no papel do professor na chamada sociedade da informação e do conhecimento. 


\section{O papel do professor}

No presente contexto em que as vias de acesso ao conhecimento não dependem exclusivamente da instituição escolar ou universitária, o papel do professor também tende a reformular-se. Ao contrário do que acontece no modelo tradicional de educação no qual o professor detém o poder, visto que detém o conhecimento. O perfil de professor esperado para atender as necessidades da sociedade atual aproxima-se mais da figura de um provocador do que de um transmissor de conhecimentos. Isso porque a formação de sujeitos críticos e dotados de competências como a criatividade, a flexibilidade, a capacidade de resolver problemas tornam-se atributos indispensáveis para atuação na sociedade atual (TERUYA, 2006).

Sendo assim, o professor torna-se um incansável consumidor de informações para que consiga dialogar com seus alunos cada vez mais atentos ao que acontece no mundo. A título de exemplificação, se pensarmos na desigual concorrência entre a aula de matemática e o videogame, as redes sociais, aí sim teremos motivos para nos preocuparmos e nos apropriarmos de métodos e técnicas alternativas para tornar a nossa prática de ensino menos enfadonha e mais interessante. Na sociedade da informação e do conhecimento a educação escolar disputa a atenção dos alunos com outros espaços sociais mais atraentes e dinâmicos e é nesse momento que o papel do professor deve ser repensado para desenvolver alternativas metodológicas que permitam a construção do conhecimento e o desenvolvimento da autonomia do aprendiz (ALTOÉ, 2003).

Cabe lembrar que um ponto importante a ser discutido repousa na formação profissional do professor, essa que não pode acontecer apenas na graduação, mas deve ter continuidade para oferecer condições aos professores de apropriarem-se da teoria e relacioná-la com a prática. Acreditamos que a melhoria do processo educativo se dá também pelo investimento na formação continuada do professor. Segundo Barros e Moraes (2002) para que a qualidade do processo educativo ocorra torna-se necessário que a formação do professor seja repensada a fim de atingir a profissionalização dos educadores e o desenvolvimento de sua criticidade.

Há uma necessidade real de que os educadores comprometidos com o processo educativo se lancem à produção ou assimilação crítica de inovações de caráter pedagógico, podendo, assim, aproveitar o estreito espaço de movimento existente no campo educacional, para gerar mudanças que não sejam simples expressões da modernidade (BRITO; PURIFICAÇÃO, 2008, p. 24). 
Se por um lado o discurso da democratização do conhecimento simula uma dimensão menos centralizadora e mais socializante do conhecimento, por outro, revela a ênfase dada pela mídia ao discurso de uma educação redentora, atribuindo à educação um papel social que não lhe cabe. Na perda da sua especificidade como instituição de formação humana e responsável pelo acesso do aprendiz ao conhecimento científico, a educação escolar deixa de proporcionar tanto ao aprendiz quanto ao professor a experiência de conhecer os recursos tecnológicos e as linguagens a ele inerentes. Fato esse, entre outros, que distancia o professor do seu processo de formação continuada e no desenvolvimento de novas alternativas atitudinais e procedimentais. Outro ponto importante rumo à mudança de paradigma na formação do professor diz respeito à reformulação de políticas educacionais a fim de que o profissional da educação tenha condições objetivas para realizar uma prática pedagógica menos tradicional e mais inovadora.

\section{Considerações finais}

A partir do referencial teórico adotado neste artigo buscamos discorrer brevemente sobre a concepção de sociedade da informação e do conhecimento e o surgimento de novos desafios apresentados tanto à formação quanto à atuação do professor. Esse que deve conhecer a especificidade de seu trabalho e as implicações decorrentes dos avanços científicos e tecnológicos na sua prática pedagógica para ter condições de promover a análise crítica e a reflexão.

Ao compreender o seu papel como agente responsável em promover o desenvolvimento da análise crítica e reflexiva de seus alunos, o professor estará repensando a sua prática voltada para a formação de sujeitos conscientes de seu papel como agente transformador na sociedade (BRITO; PURIFICAÇÃO, 2008). Para tanto, além de dominar o conteúdo que ensina e de buscar a mais adequada metodologia para trabalhá-lo, o professor atualmente deve ser capaz de se "apropriar das diferentes linguagens existentes no mundo da mídia, não apenas decifrar os códigos, mas também estar munido de uma interpretação crítica dos conteúdos que circulam nos diversos meios de comunicação" (TERUYA, 2006, p. 81).

Portanto, a discussão aqui realizada aponta para a necessidade de conhecer os pressupostos da sociedade da informação e do conhecimento, visto que interferem diretamente na educação escolar promovendo o repensar sobre o papel e a formação do professor. Assim, buscamos no limite do referencial teórico aqui adotado compreender os reflexos deste momento histórico em que 
as tecnologias da informação e comunicação ganham destaque e promovem mudanças significativas na dinâmica social exigindo um novo perfil de homem com formação diferenciada.

\section{REFERÊNCIAS}

ALTOÉ, Anair. Formação de professores para o uso do computador em sala de aula. Teoria e prática da educação, Maringá: DTP/UEM, v. 6, n. 14, p. 483-496, edição especial, 2003.

BARROS, Marta S. F.; MORAES, Sílvia P. G. de. Formação de professores: expressão da complexidade da prática pedagógica. In: MACIEL, L. S. B. et al. (Org.). Formação de professores e prática pedagógica. Maringá, PR: Eduem, 2002. p. 15-31.

BIANCHETTI, Lucídio. Da chave de fenda ao laptop. Tecnologia digital e novas qualificações: desafios à educação. Petrópolis/Florianópolis: Editora Vozes/Editora da UFSC, 2001.

BRITO, Gláucia da S.; PURIFICAÇÃO, I. Educação e novas tecnologias. 2. ed. Curitiba: Ibpex, 2008.

CASTELLS, Manuel. A sociedade em rede. Vol I. 3. ed. São Paulo: Ed. Paz e Terra, 2000.

FRIGOTTO, Gaudêncio. Educação e a crise do capitalismo real. 2. ed. São Paulo: Cortez, 1996.

LÉVY, Pierre. Cibercultura. Tradução de Carlos Irineu da Costa. São Paulo: Editora 34, 1999.

MATTELART, Armand. História da sociedade da informação. 2. ed. Revista e atualizada. São Paulo: Edições Loyola, 2006.

NAGEL, Lízia H. A sociedade do conhecimento no conhecimento dos educadores. Revista Urutágua. Maringá, PR, ano I, n. 04, maio. 2002. Disponível em: < http://www. urutagua.uem.br//04edu_lizia.htm > Acesso em: 19/10/2012.

SCHAFF, Adam. A sociedade informática. 4. ed. São Paulo: Universidade Paulista/ Editora Brasiliense, 1995.

TERUYA, Tereza K. Trabalho e educação na era midiática: um estudo sobre o mundo trabalho na era da mídia e seus reflexos na educação. Maringá, PR: Eduem, 2006.

Texto recebido em 18 de janeiro de 2010.

Texto aprovado em 10 de março de 2010. 
